\title{
What Is Old Is New Again: Investigating and Analyzing the Mysteries of the Claustrum
}

\author{
John Darrell Van Horn ${ }^{1}$ iD \\ Published online: 7 January 2019 \\ (C) Springer Science+Business Media, LLC, part of Springer Nature 2019
}

There is something particularly exciting about being on the vanguard of a new movement or burgeoning area of neuroscientific study. The newness of it all; the uncharted territory; the thrill of discovering new things; the growth of community. While from the scale and scope of the recent Society for Neuroscience Annual Meeting in San Diego (Nov. 4-7, 2018) it might seem that anything and everything about the brain is being closely scrutinized, tested, explored, and measured. Nonetheless, the "new" can still be found. Where it can be, excitement and wonder abound.

Over the past year, I was fortunate to serve as the President of the Society for Claustrum Research - a small but passionate group of international researchers with an intense interest in characterizing and understanding the claustrum (http:// claustrumsociety.org/). A thin, irregularly shaped structure, located bilaterally between the insular cortices and the putamen, and sandwiched between the external and extreme capsules, the clasutrum is enigmatic and its function undetermined. A nascent community has grown around mutual efforts to reveal its mysteries.

A seminal article by Christof Koch and the late Sir Francis Crick (b1916 - d2004) energized modern interest in the claustrum and its putative functional role. ${ }^{1}$ Yet, the structure was first illustrated in the beautiful neuroanatomical treatise of Félix Vicq d'Azyr, ${ }^{2}$ French anatomist, historian, social reformer, and

\footnotetext{
${ }^{1}$ Crick, F.C., Koch C.(2005). What is the function of the claustrum?. Philosophical Transactions of the Royal Society of London. Series B, Biological Sciences ,360(1458), 1271-1279.

${ }^{2}$ Vicq d'Azyr, F. (1786). Traité d'anatomie et de physiologie - avec des planches colorës représentant au naturel les divers organes de 'Homme et des Animaux. Paris: F.A. Didot.
}

John Darrell Van Horn

jvanhorn@usc.edu

1 USC Mark and Mary Stevens Neuroimaging and Informatics Institute, Laboratory of Neuro Imaging (LONI), Keck School of Medicine, University of Southern California, Los Angeles, CA, USA personal physician to Marie Antoinette. ${ }^{3}$ Its diminutive size and uncertain functional significance has since made its neuroanatomical study challenging or deemed otherwise unimportant. Though studies in macaques, ${ }^{4}$ rats, ${ }^{5}$ pigs, ${ }^{6}$ tree shrews, ${ }^{7}$ and other species have been conducted in some number, in vivo neuroimaging examinations in the human have been rare. ${ }^{8}$

Recently, however, new research has underscored the uniqueness of the claustrum, which now might be ready to give up its secrets. ${ }^{9}$ As an anatomical nuclei, it is distinct from the adjacent endopiriform cortex ${ }^{10}$ as evident in the mouse. The relatively low diversity of cell types was investigated in human claustra by Braak and Braak ${ }^{11}$ and, based on Golgi lipofuscin granular staining, shown to comprise five types of neurons - combinations of spiny and aspiny

\footnotetext{
${ }^{3}$ Tubbs, R.S., Loukas, M., Shoja, M.M., Mortazavi, M.M., Cohen-Gadol, A.A. (2011). Félix Vicq d'Azyr (1746-1794): Early founder of neuroanatomy and royal French physician. Child's Nervous System, 27(7), 1031-1034.

${ }^{4}$ Gattass, R., Soares, J.G., Desimone, R., Ungerleider, L.G. (2014). Connectional subdivision of the claustrum: two visuotopic subdivisions in the macaque. $D-101477946$. 8:63.

${ }^{5}$ Smith, J.B., Liang, Z., Watson, G.D.R., Alloway, K.D., Zhang, N. (2017). Interhemispheric resting-state functional connectivity of the claustrum in the awake and anesthetized states. Brain Structure \& Function, 222(5), 20412058.

${ }^{6}$ Pirone, A., Miragliotta, V., Ciregia, F., Giannessi, E., Cozzi, B. (2018). The catecholaminergic innervation of the claustrum of the pig. Journal of Anatomy, 232(1), 158-166.

${ }^{7}$ Carey, R.G., Bear, M.F., Diamond, I.T. (1980). The laminar organization of the reciprocal projections between the claustrum and striate cortex in the tree shrew, Tupaia glis. Brain Research, 184(1), 193-198.

${ }^{8}$ Fernandez-Miranda, J.C., Pathak, S., Engh, J., et al. (2012). High-definition fiber tractography of the human brain: neuroanatomical validation and neurosurgical applications. Neurosurgery, 71(2), 430-453.

${ }^{9}$ Brown, S.P., Mathur, B.N., Olsen, S.R., Luppi, P.H., Bickford, M.E., Citri, A. (2017). New breakthroughs in understanding the role of functional interactions between the Neocortex and the Claustrum. The Journal of Neuroscience, 37(45), 10877-10881.

${ }^{10}$ Watson, C., Puelles, L. (2016). Developmental gene expression in the mouse clarifies the organization of the claustrum and related endopiriform nuclei. Journal of Comparative Neurology

${ }^{11}$ Braak, H., Braak, E. (1982). Neuronal types in the claustrum of man. Anatomy and Embryology (Berlin) 163(4), 447-460.
} 
nerve cells having varying morphometries. Further neuronal classification has been performed in the rabbit ${ }^{12}$ as well as the cat, ${ }^{13}$ where multiple classes of projection neurons and interneurons were noted throughout the entirety of the claustrum.

Its functional role in the brain still remains largely theoretical, however. Crick and Koch, in their famous paper, suggested that the claustrum serves as the conductor of the orchestra of neural activity and controls what is allowed into conscious attention. A recent case study of a neurological patient having the surgical implantation of depth electrodes into the claustrum certainly lends support to this notion. ${ }^{14}$ With the electrical current turned off, the patient can read passages from a magazine without difficulty, but when the current is suddenly turned on, the patient freezes mid-sentence into what appears to be an absence-like seizure, only to continue reading again once the current has been turned off again. By contrast, however, studies in rats have suggested that the claustrum should not be universally regarded as an integrator of somesthetic and motor information. ${ }^{15}$

The claustrum may play a role in a range of neurologic and clinical syndromes - from psychiatric symptoms resulting from copper deposition in patients with Wilson's Disease, ${ }^{16}$ to dopamine content in Parkinson's Disease sufferers, ${ }^{17}$ to a putative role in schizophrenia. ${ }^{18}$ The claustrum may very well be a regional "skeleton key" which is at the root of, but also which links and contributes to, a variety of brain disorders. Where identified as an activation hot-spot in functional neuroimaging studies in healthy subjects, however, it is only as a secondary, tertiary, or otherwise tangential loci - recognized but with little fanfare (see Meador et al. ${ }^{19}$, for instance).

\footnotetext{
$\overline{12}$ Wasilewska, B., Najdzion, J. (2001). Types of neurons of the claustrum in the rabbit-Nissl, Kluver-Barrera and Golgi studies. Folia Morphologica 60(1), $41-45$.

${ }^{13}$ Rahman, F.E., Baizer, J.S. (2007). Neurochemically defined cell types in the claustrum of the cat. Brain Research, 1159:94-111.

${ }^{14}$ Koubeissi, M.Z., Bartolomei, F., Beltagy, A., Picard, F. (2014). Electrical stimulation of a small brain area reversibly disrupts consciousness. Epilepsy and Behavior, 37:32-35.

${ }^{15}$ Smith, J.B., Radhakrishnan, H., Alloway, K.D. (2012). Rat claustrum coordinates but does not integrate somatosensory and motor cortical information. The Journal of Neuroscience, 32(25):8583-8588.

${ }^{16}$ Sener, R.N. (1993). The claustrum on MRI: Normal anatomy, and the bright claustrum as a new sign in Wilson's disease. Pediatric Radiology, 23(8), 594 596.

${ }^{17}$ Sitte, H.H., Pifl, C., Rajput, A.H (2017). Dopamine and noradrenaline, but not serotonin, in the human claustrum are greatly reduced in patients with Parkinson's disease: Possible functional implications. The European Journal of Neuroscience, 45(1), 192-197.

${ }^{18}$ Patru, M.C., Reser, D.H. (2015). A new perspective on delusional states evidence for Claustrum involvement. Frontiers in Psychiatry, 6:158.

${ }^{19}$ Meador, K.J., Revill, K.P., Epstein, C.M., Sathian, K., Loring, D.W., Rorden, C. (2017). Neuroimaging somatosensory perception and masking. Neuropsychologia, 94:44-51.
}

Important in the context of neuroinformatics is the growing appreciation of the rich white matter connectivity of the claustrum. ${ }^{20}$ Examination of the connectivity and its network properties using diffusion weighted imaging tractography in humans has indicated dense and wide-spread connections between that claustrum and nearly all portions of the cerebral cortex. ${ }^{21}$ Graph-theoretical analysis from the rats has suggested that the claustrum may be a previously heretofore unappreciated member of the so-called "rich club" of inter-connected regional brain hubs ${ }^{22}$ - a result which has also been reported in brain imaging studies of human connectivity. ${ }^{23}$ As a "rich club" member, with its poundfor-pound wide-reaching connectivity, the claustrum may, indeed, play a fundamental role in a range of cognitive operations. Specifically, in line with Crick and Koch, it may serve to synthesize sensory information and feed it forward into one's conscious experience.

While having its neuroanatomical descriptive origins in eighteenth century France, the claustrum today represents one of the last brain regions to come under the full scrutiny of modern neuroscience. Like the equally mysterious zona incerta, ${ }^{24}$ the claustrum may be turn up from time-to-time in published results but its importance little appreciated let alone understood. The analysis of the cellular composition, form, connectivity, and function of the claustrum represents a major challenge and here is where neuroinformatics can make an enormous contribution. With advances in the examination of brain connectivity in human ${ }^{25}$ and in non-humans ${ }^{26}$ and the availability of novel mathematical frameworks for analysis, ${ }^{27}$ perhaps the next few years will see fuller computational and conceptual innovations for claustral characterization. ${ }^{28}$ These

\footnotetext{
${ }^{20}$ Torgerson, C.M., Van Horn, J.D. (2014). A case study in connectomics: The history, mapping, and connectivity of the claustrum. Frontiers in Neuroinformatics, $8: 83$.

${ }^{21}$ Torgerson, C.M., Irimia, A., Goh, S.Y.M., Van Horn, J.D. (2015). The DTI connectivity of the human claustrum. Human Brain Mapping, 36(3):827-838.

${ }^{22}$ Swanson, L.W., Sporns, O., Hahn, J.D. (2016). Network architecture of the cerebral nuclei (basal ganglia) association and commissural connectome. Proceedings of the National Academy of Sciences of the United States of America, 113(40), E5972-E5981.

${ }^{23}$ Bhattrai, A., Irimia, A., Torgerson, CM., Van Horn, JD. (2017). Neuroimaging analysis of white matter connectivity between the claustrum and the rich-club network of the human brain. Twenty-Third Annual Meeting of the Organization on Human Brain Mapping; June 25-29, 2017, Vancouver, Canada.

${ }^{24}$ Chou, X.L., Wang, X., Zhang, Z.G., et al. (2018). Inhibitory gain modulation of defense behaviors by zona incerta. Nature Communications, 9(1), 1151.

${ }^{25}$ Glasser, M.F., Smith, S.M., Marcus, D.S., et al. (2016). The human Connectome Project's neuroimaging approach. Nature Neuroscience, 19(9), $1175-1187$.

${ }^{26}$ Hintiryan, H., Foster, N.N., Bowman, I., et al. (2016). The mouse corticostriatal projectome. Nature Neuroscience.

${ }^{27}$ Zingg, B., Dong, H.W., Tao, H.W., Zhang, L.I. (2018). Input-output organization of the mouse claustrum. Journal of Comparative Neurology, 526(15), $2428-2443$.

${ }^{28}$ Johnson, J.I., Fenske, B.A., Jaswa, A.S., Morris, J.A. (2014). Exploitation of puddles for breakthroughs in claustrum research. $D-101477946.8: 78$.
} 
may, finally, reveal a satisfying description of the claustrum and its role in cognition, conscious attention, and in clinical syndromes.

It is comforting to know that new discoveries and descriptions of "old" brain regions remain possible which can continue to motivate and propel our understanding of the human nervous system. Modern basic and neuroinformatics research conducted on the claustrum is one such area. Perhaps that is the essence and wonder of neuroscience - what is old can be new again.

Publisher's Note Springer Nature remains neutral with regard to jurisdictional claims in published maps and institutional affiliations. 